\title{
ANTI-HISTONE H1 IgGs POSSESS PROLIFERATIVE ACTIVITY TOWARDS HUMAN T-LEUKAEMIA CEM CELLS
}

\author{
Yu. Kit ${ }^{1, *}$, I. Magorivska ${ }^{1}$, R. Bilyi ${ }^{2}$, S. Myronovskij ${ }^{1}$, R. Stoika ${ }^{1}$ \\ ${ }^{1}$ Institute of Cell Biology, the National Academy of Sciences of Ukraine, Lviv 79005, Ukraine \\ ${ }^{2}$ Danylo Halytsky Lviv National Medical University, Lviv 79010, Ukraine
}

\begin{abstract}
The aim of this study was to characterize the proliferative activity of the anti-histone H1 IgGs towards human T-leukaemia CEM cells. Materials and Methods: Anti-histone H1 IgGs were purified from blood serum of systemic lupus erythematosus patients by precipitation of serum proteins with $50 \%$ ammonium sulfate followed by a sequential affinity chromatography on Protein GSepharose and histone H1-Sepharose columns. To avoid contamination with other proteins, anti-histone H1 IgGs were subjected to strongly acidic pH 2.0 during gel filtration through HPLC column. The effects of the anti-histone H1 IgGs on cell viability and cell cycle were tested by MTS-assay and flow cytometry, correspondingly. The cross-reactivity of the anti-histone H1 antibodies towards heterogenetic and cellular antigens was evaluated by Western-blot analysis. Results: It was found that incubation of CEM cells with the HPLC-purified anti-histone H1 IgGs resulted in significant stimulation of cell growth by $46 \%$ after $48 \mathrm{~h}$ of incubation. These IgGs possess an antigenic poly-specificity to positively charged heterogenetic antigens and different cellular antigens. FITC-labeled and biotinylated anti-histone H1 IgGs are internalized by CEM cells and preferentially accumulated in the cytoplasm. Conclusion: The anti-histone H1 IgGs are shown to internalize human T-leukemia CEM and stimulate their proliferation. These IgGs are polyspecific toward cellular antigens.
\end{abstract}

Key Words: autoantibodies, IgGs, systemic lupus erythematosus, blood serum, human T-leukemia CEM cells, cross-reactivity, cell proliferation.

Targeting intracellular proteins and nucleic acids by the components of humoral immune system is a principal characteristic of the systemic autoimmune diseases. An appearance of the autoantibodies possessing reactivity with different intracellular antigens and associated with systemic autoimmune diseases was also found in cancer patients. The anti-nuclear autoantibodies play a key role since they were detected in 90\% of systemic lupus erythematosus (SLE) patients $[1,2]$ and $\sim 30 \%$ of cancer patients [3]. The reactivity of the autoantibodies with double-stranded DNA and histones is a typical and frequently observed immunologic abnormality in the SLE patients [4]. The antiDNA antibodies (Abs) found in blood serum of these patients were studied in detail and were shown to be uptaken in vitro by a variety of cells, including renal tubular cells, lymphocytes, Chinese hamster ovary cells, and transformed hamster fibroblasts $[5,6]$. Former studies of structure, functions, and pathogenicity of the antiDNA autoantibodies revealed their dual role - double substrate specificity (hydrolysis of DNA and RNA) and toxicity towards tumor cell lines [7]. Although the antihistone Abs were found in both cancer and rheumatic autoimmune patients [8], their effect towards tumor cells remains poorly studied. Earlier, we have shown that IgGs purified from blood serum of the multiple myeloma patients by means of the affinity chromatography on calf thymus histone $\mathrm{H} 1$-Sepharose column were capable to stimulate proliferation of T-leukemia CEM cells in vitro [9]. The proliferative effect of the antihistone $\mathrm{H} 1 \mathrm{Abs}$ isolated from blood serum of the SLE

Submitted: November 26, 2015

*Correspondence: E-mail: kit@cellbiol.Iviv.ua

Abbreviations used: Abs - antibodies; SLE - systemic lupus erythematosus. patients and human milk towards different lines of tumor cells was also demonstrated in vitro [10, 11]. However, the mechanisms of such interaction of these lgGs with tumor cells, as well as their antigenic characteristics remained unknown.

Here we demonstrated that the proliferative antihistone $\mathrm{H} 1 \mathrm{lgGs}$ that were purified using affinity chromatography from blood serum of the SLE patients possess the antigenic poly-specificity to different heterogenetic and cellular antigens. These IgGs were also internalized by human T-leukemia CEM cells and preferentially accumulated in their cytoplasm. Specific motives capable of interacting with Mode 1 binding site of the 14-3-3 protein and SH3-domain of tyrosineprotein kinase ITK/TSK were detected in the IgG 1 and IgG 3 subclasses by the analysis of Scansite database using a Motif Scan program.

\section{MATERIALS AND METHODS}

Patients. Blood serum was prepared from the peripheral blood of the SLE patients diagnosed according to American College of Rheumatology criteria for SLE, and healthy donors under the approval of the Review Board of the Danylo Halytsky Lviv National Medical University, in accordance with the regulations of the Ministry of Health of Ukraine. A documented consent was obtained from all patients included in the study, and the form of the informed consent was approved by the Bio-Ethics Review Board of the Danylo Halytsky Lviv National Medical University.

Cell culture. Human T-leukemia CEM cells were obtained from the Bank of Cell Lines of Human and Animal Tissues of the R.E. Kavetsky Institute of Experimental Pathology, Oncology and Radiobiology, the National Academy of Sciences of Ukraine (Kyiv, Ukraine). Cells were maintained in the RPMI- 1640 culture medium 
(Sigma Chemical Co., USA) supplemented with $10 \%$ fetal bovine serum (Sigma) and gentamycin $(50 \mu \mathrm{g} / \mathrm{ml}$, Sigma, USA). Cell cultures were maintained in the atmosphere of $5 \% \mathrm{CO}_{2}, 95 \%$ air at $37^{\circ} \mathrm{C}$ and $100 \%$ humidity.

Purification of anti-histone H1 lgGs. IgGs were obtained from blood serum of SLE patients using a sequential procedure described elsewhere [12]. Briefly, triple precipitation of blood serum proteins with the ammonium sulfate was followed with the affinity chromatography on Protein-G and histone H1-Sepharose columns. The anti-histone $\mathrm{H} 1 \mathrm{lg}$ Gs were additionally purified by a size exclusion chromatography on Perkin Elmer HPLC Series 200 system using Bio-Sil SEC 250 Column (Bio-Rad, Marnes-la-Coquette, France) in $0.1 \mathrm{M}$ Glycine- $\mathrm{HCl}, \mathrm{pH} 2.6$ buffer at $1 \mathrm{ml} / \mathrm{min}$ flow rate, as described in [12]. The protein fractions corresponding to the main peak of IgG were collected, neutralized with $1.5 \mathrm{M}$ Tris- $\mathrm{HCl}, \mathrm{pH} 8.8$, dialyzed for $18 \mathrm{~h}$ against the TBS, and further analysed by the gradient (7-16.5\%) SDS polyacrylamide gel electrophoresis at the non-reducing conditions [13].

Cell viability and proliferation assay. Cells were seeded into 96-well plate at a starting concentration of 50,000 cells $/ \mathrm{ml} .20 \mu \mathrm{g} / \mathrm{ml}$ of the Abs in the PBS were added to the cultured cells and incubated for 24, 48 and $72 \mathrm{~h}$. A part of viable cells after Abs treatment was determined by the MTT (3-[4,5-dimethylthiazol2-yl]-2,5-diphenyltetrazolium bromide; thiazolyl blue) assay as recommended by the manufacturer (Sigma, USA). $10 \mu \mathrm{l}$ of MTS/PMS solution $(2 \mathrm{mg} / \mathrm{ml} / 0.92 \mathrm{mg} / \mathrm{ml}$, $1: 20$ ) were added to each well followed by $1 \mathrm{~h}$ incubation at $37^{\circ} \mathrm{C}$ in humidified (100\%) atmosphere with 5\% $\mathrm{CO}_{2}$. The purple product of the reaction (formazan crystals dissolved in the DMSO) was quantitatively measured in a multi-channel microphotometer BioTek 76883 (BioTek, USA) at $490 \mathrm{~nm} / 630 \mathrm{~nm}$ wave length.

Flow cytometry was conducted for cell cycle analysis by using BD FACSCalibur machine (Becton Dickinson, USA) according to the manufacturer's instructions and generally accepted procedures. CEM cells were seeded into 24-well plates at starting concentration of $200,000 \mathrm{cells} / \mathrm{ml}, 20 \mu \mathrm{g} / \mathrm{ml}$ of antihistone $\mathrm{H} 1 \mathrm{lgGs}$ were added, and cells were incubated for $72 \mathrm{~h}$. Control and IgG-treated cells were collected, washed with the PBS, fixed in $70 \%$ ice-cold ethanol, and stored at $4{ }^{\circ} \mathrm{C}$. For analysis of cell cycle, the cells were transferred into the PBS, incubated with RNAse A $(10 \mu \mathrm{g} / \mathrm{ml})$ for $30 \mathrm{~min}$ at $37^{\circ} \mathrm{C}$, followed by $30 \mathrm{~min}$ treatment with $50 \mathrm{mg} / \mathrm{ml}$ propidium iodide. The intensity of fluorescence was measured by flow cytometry at $F L 2$ with $F L 2 A / F L 2 W$ cell population gating.

Cross-reactivity study. Western-blot analysis was applied for studying anti-histone H1 IgGs crossreactivity with various antigens. Total histones from calf thymus $(10 \mu \mathrm{g})$, bovine myelin basic protein $(5 \mu \mathrm{g})$, chicken egg lysozyme, bovine cytochrome $C(5 \mu \mathrm{g})$, bovine milk casein $(5 \mu \mathrm{g})$ and bovine serum albumin $(5 \mu \mathrm{g})$ were used as targeted antigens. Total cell lysates were obtained by the incubation ( $30 \mathrm{~min}$ on ice) of T-leukemia CEM cells with lysis buffer (20 mM Tris-
$\mathrm{HCl}(\mathrm{pH} 7.4), 1 \%$ Triton $\mathrm{X}-100,150 \mathrm{mM} \mathrm{NaCl}$ ) containing protease inhibitor mixture. The cell lysate was centrifuged at $12,000 \mathrm{~g}$ for $15 \mathrm{~min}$ at $4{ }^{\circ} \mathrm{C}$, and the supernatant was collected. Plasma membrane and cytosolic fraction of T-leukemia CEM cells were isolated, as described in [14]. Protein concentration in the collected fractions was measured using BioRad Protein Assay Kit (Great Britain), and the aliquots containing $30-40 \mu \mathrm{g}$ of protein were separated by the SDS-electrophoresis in $12 \%$ polyacrylamide gels [13]. The blots were incubated with $20 \mu \mathrm{g} / \mathrm{ml}$ of the antihistone $\mathrm{H} 1 \mathrm{lgGs}$ for $18 \mathrm{~h}$ at $4{ }^{\circ} \mathrm{C}$ and for $1 \mathrm{~h}$ with secondary anti-human IgG antibody covalently bound to a horseradish peroxidase. After incubation, the membrane was washed with TBST $(20 \mathrm{mM}$ Tris- $\mathrm{HCl}$ ( $\mathrm{pH} 7.4), 0.05 \%$ Tween $20,150 \mathrm{mM} \mathrm{NaCl}$ ) and developed using the ECL kit.

Intracellular accumulation of anti-histone H1 IgGs. To study the accumulation of the anti-histone H1 IgGs in CEM cells these Abs were pre-labeled with FITC. T-leukemia CEM cells were seeded into 96-well plates and incubated for $2 \mathrm{~h}$ in the presence of a mixture of FITC-labeled anti-histone $\mathrm{H} 1 \mathrm{IgGs}$ $(2 \mu \mathrm{M})$ at $37^{\circ} \mathrm{C}$ in the atmosphere of $5 \% \mathrm{CO}_{2}$. After such incubation, the cells were observed under differential interference contrast using fluorescent Zeiss Aziolmager A1 microscope (Carl Zeiss, Germany) equipped with excitation BP 470/40 nm filter and emission BP 525/50 nm filter. Imaging was conducted using AxioCam MRm digital camera (Carl Zeiss, Germany).

Intracellular accumulation of IgGs by CEM cells was also tested by incubating $10 \mu \mathrm{g} / \mathrm{ml}$ previously biotinylated anti-histone $\mathrm{H} 1 \mathrm{lgGs}$ with CEM cells for $24 \mathrm{~h}$ at standard conditions. The cytochemical analysis was performed, as described previously [14]. Briefly, the cells were washed 3 times with PBS, fixed with methanol, permeabilized with Triton X-100 (0.1\%), blocked with 5\% BSA and incubated with $1 \mu \mathrm{g} / \mathrm{ml}$ of streptavidin-Alexa546, washed, counterstained with DAPI and mounted into a permanent slide. Cells were analyzed using Zeiss LSM780 Laser Confocal System using a corresponding laser and detector wavelength, $63 \times 1.4 \mathrm{NA}$ oil immersion objective and Zen 2011 software for image processing. Cell optical sections with the thickness of $0.4 \mu \mathrm{m}$ in Z-plane were analyzed (usually the whole cell consisted of 9 to 11 such sections) for the presence of Alexa signal and of nucleic acid detected by DAPI staining. The resolution in XY-planes was $0.13 \mu \mathrm{m}$.

Penetration of the anti-histone $\mathrm{H} 1 \mathrm{lgGs}$ in T-leukemia CEM cells was also checked using Western-blot analysis. 1000,000 cells $/ \mathrm{ml}$ were incubated with $20 \mu \mathrm{g} / \mathrm{ml}$ of the biotinylated Abs for 2 or $24 \mathrm{~h}$ at $37^{\circ} \mathrm{C}$. After that, the cells were washed three times with the PBS followed by centrifugation at $1,500 \mathrm{~g}$, and the cellular cytoplasmic fraction was obtained, as described [14]. Briefly, the cells were suspended in the hypotonic buffer (10 mM Tris- $\mathrm{HCl}, \mathrm{pH} 7.5,1.5 \mathrm{mM} \mathrm{MgCl}$, $1 \mathrm{mM}$ PMSF), and then homogenized in a Potter homogenizer on ice followed with centrifugation for 
10 min at $10,000 \mathrm{~g}$. The supernatant was collected and used in Western-blot analysis.

Statistical analysis. Statistical significance of the differences between the groups was assessed by Student's $t$-test.

\section{RESULTS AND DISCUSSION}

IgGs possessing an affinity to histone $\mathrm{H} 1$ were isolated from blood serum of SLE patients using a procedure described in [9]. Since isolation of anti-histone $\mathrm{H} 1 \mathrm{IgGs}$ from blood serum by a sequential affinity chromatography does not rule out the presence of biologically active contaminants (for example, bacterial lipopolysaccharides), we used an additional purification step, namely size exclusion chromatography of IgG preparations at high acidic conditions [12]. That allowed a separation of Abs molecules from weakly and strongly bound antigens [6, 7, 9]. The chromatographic peak at $150 \mathrm{kDa}$ (Fig. 1) containing electrophoretically pure IgGs was further examined for the proliferation stimulating activity towards human leukemia CEM T-cells. To estimate cells viability and proliferative activity, MTT assay widely used to measure cytotoxicity of the studied agent, has been applied. It was found that $48 \mathrm{~h}$ incubation of CEM cells with anti-histone $\mathrm{H} 1 \mathrm{IgGs}$ resulted in significant increase (>40\%, $p<0.05$ ) of cell proliferation compared with control cells and cells incubated with IgGs collected as flow-throw from histone $\mathrm{H} 1$-Sepharose column named as unbound IgGs (Fig. 2). Besides, proliferation stimulating effect of the anti-histone $\mathrm{H} 1$ Abs towards CEM cells was confirmed by FACS analysis of cell cycle. A marked increase in the proportion of cells in $G_{2} / M$ stage and a decrease in the amount of $G_{1}$-cells were detected (Fig. 3). Thus, the anti-histone IgGs purified from blood serum of SLE patients by twostep sequential affinity chromatography, are capable of stimulating CEM cell proliferation.

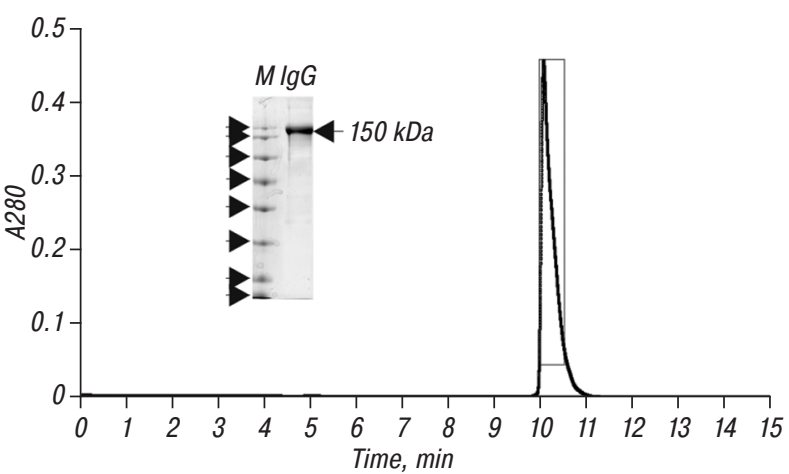

Fig. 1. Effect of highly purified anti-histone $\mathrm{H} 1 \mathrm{Abs}$ on growth and survival of CEM cells in vitro. HPLC size exclusion chromatography at $\mathrm{pH} 2.6$ of anti-histone $\mathrm{H} 1 \mathrm{lgGs}$ isolated from blood serum of SLE patients by affinity chromatography on histone $\mathrm{H} 1$-Sepharose column. IgG fraction indicated in the box was collected and used for SDS polyacrylamide gel electrophoresis (shown in the insert). M - protein molecular markers (Fermentas, Lithuania). The arrow shows the position of IgG molecules

Next, we have studied cross-reactivity of the purified anti-histone $\mathrm{H} 1 \mathrm{lgGs}$ towards different artificial antigens and potential antigenic proteins of the subfractions of CEM cells. The cationic proteins (total histones from calf thymus, bovine myelin basic protein, chicken egg lysozyme, and bovine cytochrome $\mathrm{C}$ ), as well as the non-cationic proteins (bovine casein and bovine serum albumin) were used as the artificial antigens for these IgGs. Total lysate of CEM cells was obtained and its crude membrane and cytosolic subfractions were isolated by the differential centrifugation of cell lysate in order to prepare cell antigens. Purified anti-histone $\mathrm{H} 1 \mathrm{lgGs}$ bound the cationic proteins (Fig. 4, a; lanes $1-3$ ), in contrast to the non-cationic proteins whose binding by the IgGs was not detected (Fig. 4, a, lanes 4-6). In another experiment, we observed an affinity of the anti-histone $\mathrm{H} 1 \mathrm{IgGs}$ to a variety of membrane and cytoplasmic proteins (Fig. 4, b, lanes 1-3). These data demonstrate that affinity of IgGs purified from blood serum of the SLE patients using histone H1-Sepharose column possess a cross-reactivity to different artificial cationic proteins and several cellular antigens.

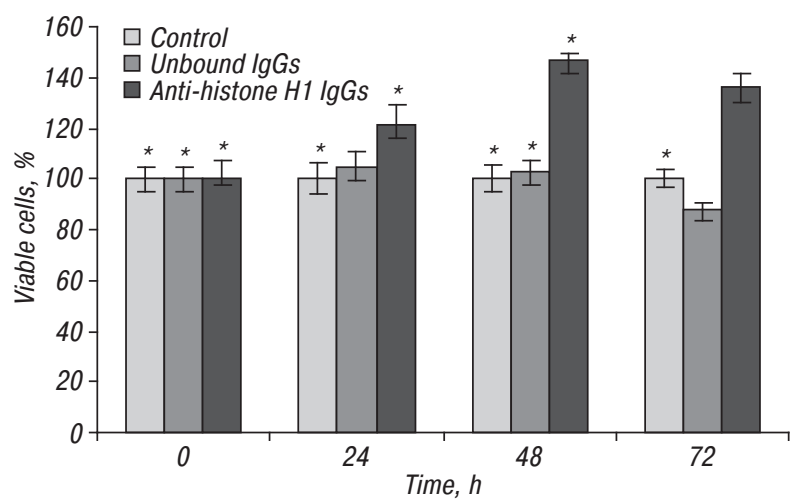

Fig. 2. The proliferation of CEM cells treated in vitro with antihistone H1 IgGs. Unbound IgGs - the IgG fraction not bound with histone $\mathrm{H} 1$-Sepharose during column affinity chromatography (flow-throw). The statistical analysis for three independent experiments is represented. ${ }^{*} p<0.05$

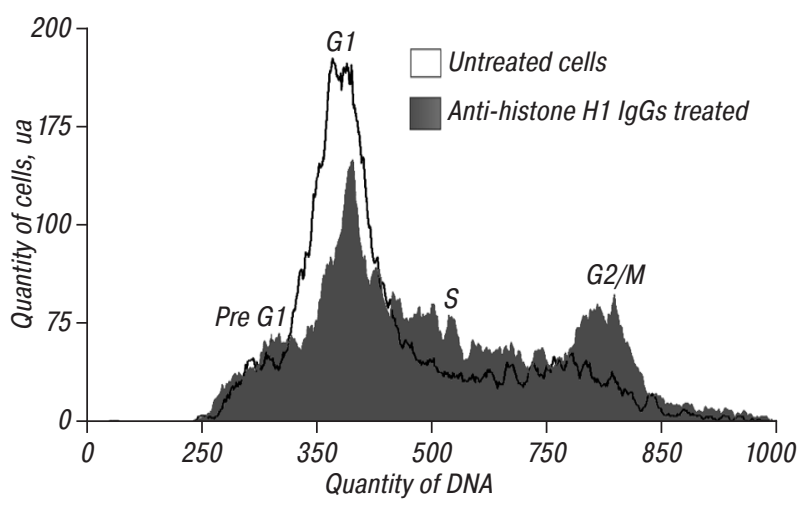

Fig. 3. FACS analysis (measurement of DNA content after propidium iodine staining) of cell cycle in the intact (black line) and anti-histone $\mathrm{H} 1 \mathrm{lgGs}$-treated (grey area) CEM leukemia cells

To determine whether the anti-histone H1 lgGs could be internalized by human T-leukemia SEM cells, the fluorescent and confocal microscopy were used. Cells were incubated for $2 \mathrm{~h}$ at $37^{\circ} \mathrm{C}$ with a fluorescently labeled Abs that caused an intensive fluorescence found mainly in cell cytoplasm (Fig. 5, a). Confocal microscopy of CEM cells treated with the biotinylated anti-histone $\mathrm{H} 1 \mathrm{lgGs}$ confirmed that suggestion (Fig. $5, b$ ). An alternative method based on the identification of IgGs present in rough-purified cytosolic 
subfraction of cells was used. CEM cells were incubated for 2 or $24 \mathrm{~h}$ with the biotinylated anti-histone H1 IgGs, then they were thoroughly washed, lysed, and the cytosolic fraction was obtained by centrifugation of damaged cells [14]. Western-blot analysis using the avidin-HRP conjugates demonstrated a presence of the IgGs in the studied cytosolic fraction (Fig. 5, c). Thus, these anti-histone $\mathrm{H} 1 \mathrm{IgGs}$ purified from blood serum of the SLE patients can be internalized by human T-leukemia SEM cells and are accumulated preferentially in the cytoplasm of treated cells.

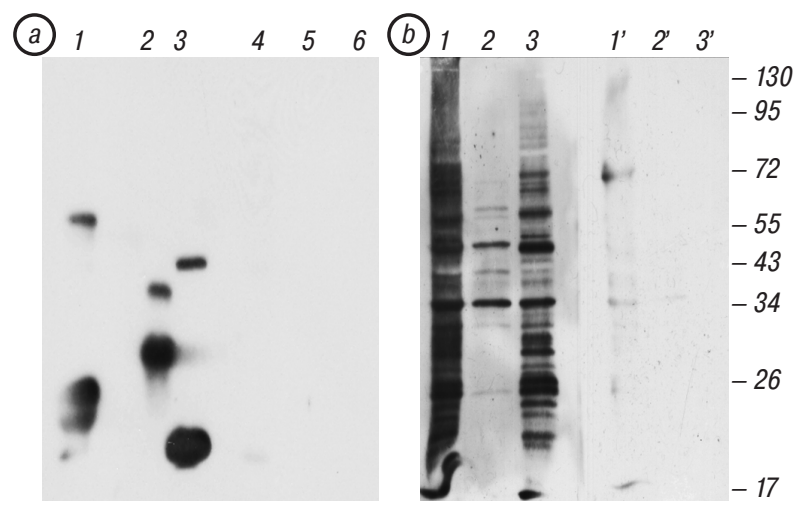

Fig. 4. Cross-reactivity of anti-histone $\mathrm{H} 1 \mathrm{IgGs}$ with heterogenetic antigens (a): total histones of calf thymus (lane 1), bovine myelin basic protein (lane 2), chicken egg lysozyme (lane 3), bovine cytochrome C (lane 4), bovine milk casein (lane 5 ), bovine serum albumin (lane 6 ); and cellular antigens $(b)$ : total lysate of CEM leukemia cells (lane 1), their cytosolic (lane 2) and membrane (lane 3 ) fractions. As a control, proteins of a total cell lysate (lane 1'), cytosolic (lane 2'), and membrane fractions (lane 3') were treated only with Avidin-HRP conjugates

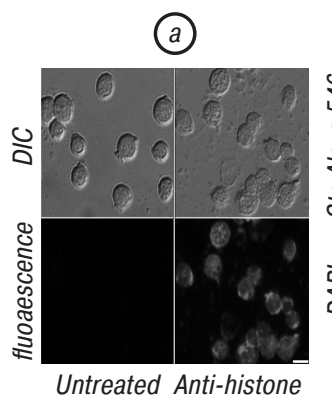

H1 lgGs treated

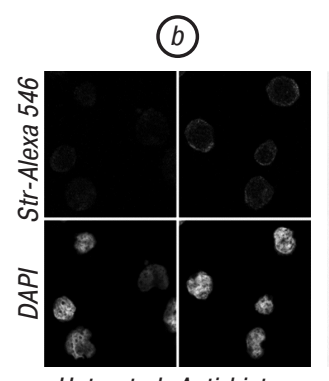

Untreated Anti-histone

H1 lgGs treated
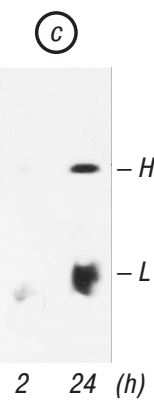

24 (h)
Fig. 5. Intracellular accumulation of the anti-histone $\mathrm{H} 1 \mathrm{lgG}$ Abs in the intact cells in vitro. (a) Results of differential interference contrast and fluorescent microscopy of CEM cells after $2 \mathrm{~h}$ incubation with FITC-labeled anti-histone H1 IgGs. (b) Confocal microscopy of intracellular accumulation of biotin-labeled antihistone $\mathrm{H} 1 \mathrm{lgGs}$ in intact CEM cells in vitro after $24 \mathrm{~h}$ incubation with these IgGs. (c) Western-blot analysis of CEM cells incubated in vitro with biotin-labeled anti-histone $\mathrm{H} 1 \mathrm{lgGs}$ for 2 and $24 \mathrm{~h}$. $\mathrm{H}$ and $\mathrm{L}-$ position of heavy and light chains of IgGs

Earlier, we have found that IgGs isolated from blood serum of the multiple myeloma and SLE patients and purified by the affinity chromatography on the histone $\mathrm{H} 1$-Sepharose column are capable of stimulating proliferation in vitro of human T-leukemia Jurkat cells $[9,10]$. Here, we addressed more detailed characterization of these Abs and the analysis of potential mechanisms responsible for their proliferative action. Besides, we have applied an additional purification step - size exclusion HPLC on the Bio-Sil SEC 250 column at very low pH 2.6 that excluded a possibility of the activity of most potential impurities in the $\lg G$ preparation [12].

The appearance of the anti-histone $\mathrm{H} 1 \mathrm{IgGs}$ in blood serum can be related to a phenomenon of the molecular mimicry of some self and foreign antigens [12]. An existence of the polyclonal and monoclonal Abs possessing cross-reactivity with histone $\mathrm{H} 1$ and other intracellular proteins and even with the carbohydrate antigens [15-17] might serve as a confirmation for such suggestion. However, the mechanisms responsible for the ability of the anti-histone $\mathrm{H} 1 \mathrm{lgGs}$ to stimulate cell proliferation are poorly understood yet. As a working hypothesis, one can suggest that these Abs possess cross-reactivity to cellular antigens that directly or indirectly activate growth factor receptors present on tumor cells via binding with specific cell surface antigens [18, 19]. We have demonstrated a cross-reactivity of the anti-histone $\mathrm{H} 1 \mathrm{lgGs}$ with different proteins (potential natural antigens) of CEM cells. Earlier, we have used similar procedure (affinity chromatography on the columns with Protein $\mathrm{A}$ and with Histone H1-Sepharose) and showed that secretory IgAs purified from the colostrum of healthy mothers were capable of stimulating proliferation in vitro of leukemia cells [11].

Another mechanism, which might be important for expression of the proliferation-stimulating activity of the anti-histone $\mathrm{H} 1 \mathrm{IgGs}$ could be linked with the internalization of these Abs by the treated CEM cells. It was found that the Abs possessing antigenic specificity towards nuclear antigens could penetrate into the target cells [20-22]. Since linker histone $\mathrm{H} 1$ is present in cell nucleus where it participates in chromatin rearrangement [23], one can speculate that stimulation of proliferation of T-leukemia CEM cells is related to internalization of the anti-histone IgGs by the targeted tumor cells and further translocation of these Abs into the cell nucleus.

To answer a question why the anti-histone IgGs can stimulate proliferation of CEM cells, we carried out a search in functional domains of the IgG molecules regarding a presence of domains that might be directly or indirectly involved in the induction of cell proliferation. As a result of such search, we found that the hinge region located in central part of the heavy chains of $\lg G$ and $\lg A$ idiotypes is rich in proline residues [24]. It is known that proline-rich motives of different cellular proteins are involved in the formation of a signaling network in the eukaryotic cells through their interaction with the SH3-domains of other proteins $[25,26]$. Thus, we hypothesized that the proline-rich motive of the IgGs might interact with specific functional domains of the intracellular proteins involved in growth-promoting signaling. To check this possibility, we tried to determine possible functional motives in primary sequences [27] of the hinge regions of human IgGs. Scansite database and Motif Scan program (scansite. mit.edu) were used to reach that goal. The results of our analysis are presented in the Table. It was found that hinge region of $\lg \mathrm{G} 1$ and $\lg \mathrm{G} 3 \mathrm{mo}-$ 
lecules contains the motives capable of interacting with the Mode 1 binding site of the 14-3-3 protein and Src-kinase homology 3 (SH3)-domain of the tyrosineprotein kinase ITK/TSK known as an interleukin-2inducible T-cell kinase or shortly ITK. 14-3-3 proteins belong to a family of conserved regulatory molecules expressed in all eukaryotic cells, and they are capable of binding numerous functionally diverse signaling proteins, including kinases, phosphatases, and transmembrane receptors [28]. The tyrosine-protein kinase ITK/TSK (EC $=2.7 .10 .2)$ plays an essential role in the regulation of the adaptive immune response. The antigen presenting cells activate $\mathrm{T}$-cell receptor that allows a recruitment of the ITK to the cell membrane, followed by a series of phosphorylation of cellular signaling proteins, finally leading to lymphokine production, cell proliferation, and differentiation [29, 30]. It was found that the anti-histone $\mathrm{H} 1 \mathrm{Abs}$ modulated the tolerogenic status of the dendritic cells and decreased cytotoxicity of the lymphokine-activated killer cells and human natural killer cells [31]. Thus, the anti-histone H1 Abs can decrease cellular immune reactivity in cancer patients, and, in that way, these auto-Abs might be involved in tumor development.

Table. Motives within primary sequences of hinge region of different IgG subclasses that were predicted by the analysis using resources of Scansite.mit.edu

\begin{tabular}{ccc}
\hline Subclasses of $\operatorname{lgG}$ & Hinge sequences & Predicted motives \\
\hline $\lg \mathrm{G} 1$ & EPKSCDKTHTCPPCP & $14-3-3$ Mode 1 binding site \\
$\lg \mathrm{G} 2$ & ERKCCVTCPPCP & Not found \\
$\lg 3$ & ELKTPLGDTTTCPRCP & Not found \\
& EPKSCDTPPPCPRCP & Itk SH3 \\
& EPKSCDTPPPCPRCP & Itk SH3 \\
& EPKSCDTPPCPRCP & Itk SH3 \\
$\lg 4$ & SPNMVPHAHHAQ & Not found \\
\hline
\end{tabular}

Note: $14-3-3$ Mode 1 binding site - binding site of the adapter protein 14-3-3. Itk SH3 - Src-kinase homology SH3-domain of tyrosine-protein kinase ITK/NSK.

Obtained data suggest that the isolated anti-histone $\mathrm{H} 1 \mathrm{lgGs}$ belong to "anti-tumor immunoglobulins" described in [32]. The authors predicted an existence of certain B-lymphocyte clones producing anti-tumor Abs that, under certain conditions, contribute to tumor growth. These Abs can be represented in blood serum by IgG or IgM subclasses and be involved in stimulation of tumor growth realized via their negative effect on T-lymphocytes, decreased activity of cytotoxic lymphocytes, and induction of T-cell tolerance.

On the other hand, there are data showing that proliferative effect of some Abs is tightly linked with their affinity to cellular receptors involved in cell proliferation. For instance, the level of autoantibodies specific to estrogen receptor alpha correlates with breast cancer cell proliferation [33], and the autoantibodies against cell-surface GRP78 promote tumor growth in a murine model of melanoma [34].

\section{CONCLUSION}

The anti-histone $\mathrm{H} 1 \mathrm{lgGs}$ isolated from blood serum of the SLE patients were additionally purified using HPLC conducted under strongly acidic conditions excluding activity of potential protein impurities. The ability of these IgGs to stimulate proliferation of hu- man T-leukemia CEM cells was demonstrated. Such activity is in agreement with a revealed antigenic polyspecificity of these IgGs towards cellular antigens, as well as with their internalization by the treated cells.

\section{CONFLICT OF INTERESTS}

The authors declare that they have no conflict of interests.

\section{ACKNOWLEDGMENT}

The authors express their gratitude to Dr. Wanda Kłopocka and Dr. Wojciech Brutkowski (Laboratory of Confocal Microscopy at Nencki Institute of Experimental Biology, Warsaw, Poland) for a support and help in the confocal microscopy, and Prof. Valentyna Chop'yk, Drs. Yaroslav Tolstayk and Iryna Kril for providing blood sera of SLE patients.

\section{REFERENCES}

1. Tan EM, Shi FD. Relative paradigms between autoantibodies in lupus and autoantibodies in cancer. Clin Exp Immunol 2003; 134: 169-77.

2. Sherer Y, Gorstein A, Fritzler MJ, Shoenfeld Y. Autoantibody explosion in systemic lupus erythematosus: more than 100 different antibodies found in SLE patients. Semin Arthritis Rheum 2004; 34: 501-37.

3. Gómez-Puerta JA, Burlingame RW, Cervera R. Antichromatin (anti-nucleosome) antibodies: diagnostic and clinical value. Autoimmun Rev 2008; 7: 606-11.

4. Burlingame RW, Boey ML, Starkebaum G, Rubin RL. The central role of chromatin in autoimmune responses to histones and DNA in systemic lupus erythematosus. J Clin Invest 1994; 94: 184-92.

5. Gabibov AG, Kozyr AV, Kolesnikov AV. Disease association and cytotoxic effects of DNA-hydrolyzing autoantibodies. Chem Immunol 2000; 77: 130-56.

6. Kozyr AV, Sashchenko LP, Kolesnikov AV, et al. AntiDNA autoantibodies reveal toxicity to tumor cell lines. Immunol Lett 2002; 80: 41-7.

7. Belogurov A Jr, Kozyr A, Ponomarenko N, Gabibov A. Catalytic antibodies: balancing between Dr. Jekyll and Mr. Hyde. Bioassays 2009; 3: 1161-71.

8. Shen GQ, Shoenfeld Y, Peter JB. Anti-DNA, antihistone, and antinucleosome antibodies in systemic lupus erythematosus and drug-induced lupus. Clin Rev Allergy Immunol 1998; 16: 321-34.

9. Magorivska I, Bilyy R, Shalay O, et al. Blood serum immunoglobulins of patients with multiple myeloma are capable of hydrolyzing histone H1. Exp Oncol 2009; 31: 97-101.

10. Kit Y, Magorivska I, Bilyy R, et al. Novel biological activity of antinuclear auto-antibodies. 3-rd Congress of Ukrainian Society of Cell Biology with the International Representatives. In: Abstract Book, May 16-20, 2012. Livadia, Yalta: 133.

11. Starykovych MO, Stoika RS, Kit YuYa. Mitotic activity of anti-histone H1 sIgA-antibodies from milk of healthy mothers. Biopolymers Cell 2013; 29: 117-23.

12. Magorivska IB, Bilyy RO, Havrylyuk AM, et al. Antihistone $\mathrm{H} 1 \mathrm{IgGs}$ from blood serum of systemic lupus erythematosus patients are capable of hydrolyzing histone $\mathrm{H} 1$ and myelin basic protein. J Mol Recognit 2010; 23: 495-502.

13. Laemmli UK. Cleavage of structural proteins during the assembly of the head of bacteriophage T4. Nature 1970; 227: $680-5$.

14. Bilyy R, Kit YY, Hellman U, et al. In vivo expression and characteristics of novel alpha-D-mannose-rich glycoprotein markers of apoptotic cells. Cell Biol Int 2005; 29: 920-8. 
15. Jarjour WN, Minota S, Roubey RA, et al. Autoantibodies to nucleolin cross-react with histone $\mathrm{H} 1$ in systemic lupus erythematosus. Mol Biol Rep 1992; 16: 263-6.

16. Baumba VA, Seferiadis K. Rabbit anti-HMG-17 antibodies recognize similar epitopes on the HMG-17 molecule as lupus autoantibodies. Relation with histone $\mathrm{H} 1$ defined epitopes. J Pept Sci 2002; 8: 683-94.

17. Christensen PA, Danielczyk A, Ravn P, et al. A monoclonal antibody to Lewis $\mathrm{Y} /$ Lewis b revealing mimicry of the histone $\mathrm{H} 1$ to carbohydrate structures. Scand J Immunol 2007; 65: 362-7.

18. Yewale $C$, Baradia $D$, Vhora I, et al. Epidermal growth factor receptor targeting in cancer: a review of trends and strategies. Biomaterials 2013; 34: 8690-707.

19. Grossmann AH, Samowitz WS. Epidermal growth factor receptor pathway mutations and colorectal cancer therapy. Arch Pathol Lab Med 2011; 135: 1278-82.

20. Lim PL, Zouali M. Pathogenic autoantibodies: emerging insights into tissue injury. Immunol Lett 2006; 103: 17-26.

21. Avrameas A, Ternynck T, Nato F, et al. Polyreactive anti-DNA monoclonal antibodies and a derived peptide as vectors for the intracytoplasmic and intranuclear translocation of macromolecules. Proc Natl Acad Sci USA 1998; 95: 5601-6.

22. He W, Ladinsky MS, Huey-Tubman KE, et al. FcRnmediated antibody transport across epithelial cells revealed by electron tomography. Nature 2008; 455: 542-6.

23. Kornberg RD, Lorch Y. Twenty-five years of the nucleosome, fundamental particle of the eukaryote chromosome. Cell 1999; 98: 285-94.

24. Adlersberg JB. The immunoglobulin hinge (interdomain) region. Ric Clin Lab 1976; 6: 191-205.
25. Pawson T. Protein modules and signalling networks. Nature 1995; 373: 573-80.

26. Whisstock JC, Lesk AM. SH3 domains in prokaryotes. Trends Biochem Sci 1999; 24: 132-3.

27. Williamson MP. The structure and function of prolinerich regions in proteins. Biochem J 1994; 297 (Pt 2): 249-60.

28. Obsil T, Ghirlando R, Klein DC, et al. Crystal structure of the 14-3-3 zeta: serotonin N-acetyltransferase complex. A role for scaffolding in enzyme regulation. Cell 2001; 105: 257-67.

29. Gibson S, Leung B, Squire JA, et al. Identification, cloning, and characterization of a novel human T-cell-specific tyrosine kinase located at the hematopoietin complex on chromosome 5q. Blood 1993; 82: 1561-72.

30. Yang WC, Collete Y, Nunès JA, Olive D. Tec kinases: a family with multiple roles in immunity. Immunity 2000; 12: 373-82.

31. Nakano T, Goto S, Lai CY, et al. Involvement of autoimmunity against nuclear histone $\mathrm{H} 1$ in liver transplantation tolerance. Transpl Immunol 2008; 19: 87-92.

32. Berezhnaya NM, Chekhun VF. B lymphocytes and anti-tumor antibodies in immunostimulation of tumor growth. In: Immunology of Tumor Growth. Kyiv: Naukova Dumka, 2005: 629-36 (in Russian).

33. Maselli A, Capoccia S, Pugliese P, et al. Autoantibodies specific to estrogen receptor alpha act as estrogen agonists and their levels correlate with breast cancer cell proliferation. Oncoimmunology 2015; 5: e1074375.

34. de Ridder GG, Gonzalez-Gronow M, Ray R, Pizzo SV. Autoantibodies against cell-surface GRP78 promote tumor growth in a murine model of melanoma. Melanoma Res 2011; 21: 35-43. 